\title{
Dielectric Behaviour of Zn/Al-NO 3 LDHs Filled with Polyvinyl Chloride Composite at Low Microwave Frequencies
}

\author{
Ethar Y. Salih, ${ }^{1}$ Zulkifly Abbas, ${ }^{1,2}$ Samer Hasan Hussein Al Ali, ${ }^{3,4}$ and Mohd Zobir Hussein ${ }^{5}$ \\ ${ }^{1}$ Department of Physics, Faculty of Science, Universiti Putra Malaysia, 43400 Serdang, Selangor, Malaysia \\ ${ }^{2}$ Institute of Mathematical Research, Universiti Putra Malaysia, 43400 Serdang, Selangor, Malaysia \\ ${ }^{3}$ Laboratory of Molecular Biomedicine, Institute of Bioscience, Universiti Putra Malaysia, 43400 Serdang, Selangor, Malaysia \\ ${ }^{4}$ Faculty of Pharmacy, Isra University, P.O. Box 22, Amman 11622, Jordan \\ ${ }^{5}$ Materials Synthesis and Characterization Laboratory, Institute of Advanced Technology, Universiti Putra Malaysia, \\ 43400 Serdang, Selangor, Malaysia \\ Correspondence should be addressed to Zulkifly Abbas; za@upm.edu.my
}

Received 8 August 2014; Revised 7 November 2014; Accepted 7 November 2014; Published 3 December 2014

Academic Editor: Baibiao Huang

Copyright (C) 2014 Ethar Y. Salih et al. This is an open access article distributed under the Creative Commons Attribution License, which permits unrestricted use, distribution, and reproduction in any medium, provided the original work is properly cited.

\begin{abstract}
Recently, researchers have shown great interest in improving the thermal, mechanical, dielectric, and microwave properties of pure polymers through the use of polymer-based composites. The essential properties of polymer-based composites can be modified by varying the amount of $\mathrm{Zn} / \mathrm{Al}-\mathrm{NO}_{3}$ layered double hydroxide ( $\mathrm{LDH}$ ) added to polyvinyl chloride (PVC). Therefore, by determining the optimal ratio of LDH in the PVC matrix, the dielectric properties of PVC-LDH composites can be improved. An LDH was prepared using the coprecipitation method, while PVC-LDH composites were prepared using tetrahydrofuran (THF) as the solvent. The composites were characterised using X-ray diffraction (XRD), Fourier transform infrared spectroscopy (FTIR), and scanning electron microscopy (SEM), and room temperature dielectric measurements were investigated using an RF Impedance/Material Analyzer (Agilent 4291). The results confirmed that the prepared composites were pure. Additionally, the presence of LDH in the PVC matrix was verified. The dielectric measurements showed that an increase in the LDH concentration leads to an increase in the dielectric constant and the dielectric loss factor. When used as dielectric filler in the PVC matrix, the LDH improved the dielectric properties of the fabricated composites. The results indicate that these composites show great potential for use as microwave absorbers at low microwave frequencies.
\end{abstract}

\section{Introduction}

PVC is a thermoplastic polymer that is used widely in floor and roof tiles, window and door frames, water pipes, sheets, packing films, and electrical wires and cables because of its good dielectric and mechanical properties, ease of processing, and low cost $[1,2]$. Both the microwave and mechanical properties of PVC are controlled by the amorphous phase that forms at $95^{\circ} \mathrm{C}$, which is the glass transition temperature [2]. The dielectric properties of PVC have been studied by a number of researchers. The characteristics of PVC have also been examined through radio frequency measurements [3]. Microwave measurements on PVC were reviewed by Amrhein and Mueller [4]. The microwave properties of PVC remain stable up to $90^{\circ} \mathrm{C}$, which is near the glass transition temperature [5].

LDH (layered double hydroxide) is a layered inorganic compound, that is, composed of an ionic lamellar solid that contains infinite brucite-type layers. LDH is positively charged and contains exchangeable hydrate gallery anions. The ability of LDH to intercalate anions makes it useful as a catalyst, a tailor-made adsorbent, or a precursor material for oxides [6]. The optical properties of LDH have been found useful for solar energy applications [7]. The thermal properties of $\mathrm{LDH}$ enable the anions within the structure to be reoriented [8]. Ahmed et al. studied the thermal, optical, and dielectric properties of LDH for different molar ratios [6]. $\mathrm{LDH}$ was found to have good dielectric properties at room 
temperature. $\mathrm{LDH}$ is highly recommended for the use in the microwave applications, such as electromagnetic interference (EMI) and electromagnetic compatibility (EMC), because of the enhanced saturated magnetisation [9].

In the last decade, much research has shown that PVC properties can be enhanced by the addition of a variety of fillers, such as metal chlorides, metal carboxylates, clays, metals, and metal hydroxides [1, 10-18]. Of the aforementioned fillers, $\mathrm{LDH}$ is also known as an anion-exchanging mineral filler. LDH has attracted much interest among researchers as an efficient filler because of its observable effect on the PVC matrix $[17,18]$. Hence, PVC properties can be enhanced by many types of LDH materials. Because PVC is used in electrical wires and cables [2] and because LDH has good dielectric properties [6] and can be used for microwave applications [9], it is advantageous to study the effect of $\mathrm{LDH}$ on the PVC matrix. This study focuses on the dielectric properties of PVC-LDH composites, where the results will be compared to the dielectric properties of pure PVC.

\section{Materials and Methods}

2.1. Materials. PVC $\left(\mathrm{Mw} \approx 530 \mathrm{~g} \cdot \mathrm{mol}^{-1}\right)$ and THF $(99.8 \%)$ were supplied by Sigma-Aldrich and J. T. Baker, respectively. Other materials used, including $\mathrm{NaOH}$ (99\%), $\mathrm{Zn}\left(\mathrm{NO}_{3}\right)_{2} \cdot 6 \mathrm{H}_{2} \mathrm{O}(98.1 \%)$, and $\mathrm{Al}\left(\mathrm{NO}_{3}\right)_{3} \cdot 9 \mathrm{H}_{2} \mathrm{O}(98 \%)$, were purchased from Sigma (St Louis, MO). Deionised water was used as the solvent in the preparation of the $\mathrm{Zn} / \mathrm{Al} \mathrm{LDH}$.

2.2. Preparation of $\mathrm{LDH}$ and PVC-LDH Composites. Zn/Al$\mathrm{NO}_{3}(\mathrm{LDH})$ preparation was carried out using the coprecipitation method described by Al Ali et al. [19]. A hydrous solution containing $2 \mathrm{~mol} / \mathrm{L}$ of $\mathrm{NaOH}$ was mixed with a $250 \mathrm{~mL}$ solution containing $\mathrm{Al}^{3+}$ and $\mathrm{Zn}^{2+}$ with a molar ratio of $1: 4$ of $\mathrm{Al}^{3+}$ to $\mathrm{Zn}^{2+}$. A pH of 7 was obtained via the dropwise addition of $\mathrm{NaOH}$, which resulted in a white solution. Pure LDH was obtained by introducing nitrogen into the atmosphere to eliminate the $\mathrm{O}_{2}$ and prevent the formation of a carbonate. The white solution was aged at $70^{\circ} \mathrm{C}$ for approximately 18 hours, followed by washing and centrifuging using deionised water, and then drying at $60^{\circ} \mathrm{C}$ in an oven. Part of the powder was mixed with polyvinyl alcohol (PVA), which acted as a binder, and then pressed at 5 tons for 5 minutes to produce an $\mathrm{LDH}$ pellet.

A uniform amount of polyvinyl chloride was dissolved in THF with $500 \mathrm{rpm}$ magnetic stirring for 24 hours to obtain a homogenous solution with no precipitation of the PVC. The PVC and LDH solutions ranged from 1 to $9 \%$ wt of $\mathrm{LDH}$ in a constant amount of PVC. The PVC/LDH solution was then magnetically stirred at $60^{\circ} \mathrm{C}$ for 6 hours until a homogenous mixture was obtained. The solution was allowed to dry for 24 hours at room temperature and was then hot pressed to $1 \mathrm{~mm}$ thickness.

2.3. Characterisations. Room-temperature dielectric properties were measured via the capacitance technique (Agilent 4291B, RF-Impedance/Material analyser) in the frequency range of $1 \mathrm{MHz}$ to $1.2 \mathrm{GHz}$. The compressed pellets of the samples (PVC, LDH, and PVC-LDH composites) were placed

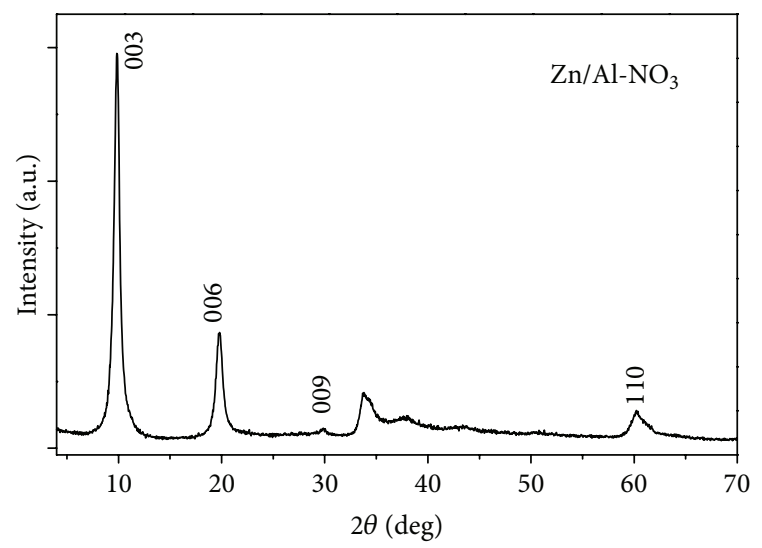

FIGURE 1: XRD patterns of $\mathrm{Zn} / \mathrm{Al}-\mathrm{NO}_{3}$.

between two plates, which served as parallel capacitors. The dielectric properties were acquired from the measured admittance of the MUT. While the presence of $\mathrm{LDH}$ in the PVC matrix was identified using X-ray diffraction patterns (XRD; Model X'PERT-PRO PANALYTICAL) using $\mathrm{CuK}_{\mathrm{a}}$ radiation with $\lambda=0.154 \mathrm{~nm}$, a current of $30 \mathrm{~mA}$, and a scanning rate of $0.06 / \mathrm{s}$ in the range $4^{\circ}-70^{\circ}$. The compact char surface (FTIR) was distinguished in the range of 400 to $4000 \mathrm{~cm}^{-1}$ on a Thermo Nicolet Nexus with a resolution of $4 \mathrm{~cm}^{-1}$. Scanning electron microscopy (SEM; Model Hitachi) at $5.00 \mathrm{KV}$ was used to confirm the homogeneous distribution of $\mathrm{LDH}$ on the surface of the PVC.

\section{Results and Discussion}

3.1. X-Ray Diffraction. Figure 1 shows the XRD patterns of the LDH particles. The LDH structure was identified by XRD diffraction patterns. The (003), (006), (009), and (110) diffraction peaks of $\mathrm{LDH}$, corresponding to the basal and higher-order reflections, were at $9.8^{\circ}, 19.8^{\circ}, 29.8^{\circ}$, and $60.25^{\circ}$, respectively. The basal spacing values for $\left(d_{003}\right),\left(d_{006}\right),\left(d_{009}\right)$, and $\left(d_{110}\right)$ were found to be $8.95,4.47,2.65$, and $1.53 \AA$, respectively. These values were obtained using the XRD software and are in good agreement with the literature [20]. According to the well-known Debye-Scherer's formula (equation (1)), the crystallite size of LDH was calculated to be $83.898 \mathrm{~nm}$ at 003 planes. Figure 2 shows the XRD patterns for the PVC$\mathrm{LDH}$ composites at varying concentrations of $\mathrm{LDH}$. There are no undesirable peaks, which confirms the purity of the prepared composites. Lack of peaks in the PVC-1\%wt LDH could be because of the low LDH concentration, which makes the region of the sample that was tested insensitive to the $\mathrm{X}$ rays. All samples were highly crystallised, as indicated by the highly intense and sharp peaks (Figure 2)

$$
D=\frac{k \lambda}{\beta \cos \theta},
$$

where the unit for $D$ is in $\mathrm{nm}, K$ is the shape factor (normally $0.9), \lambda$ is the $\mathrm{X}$-ray wavelength, and $\theta$ is the Bragg diffraction angle where the peak is observed. $\beta$ is the full width of 


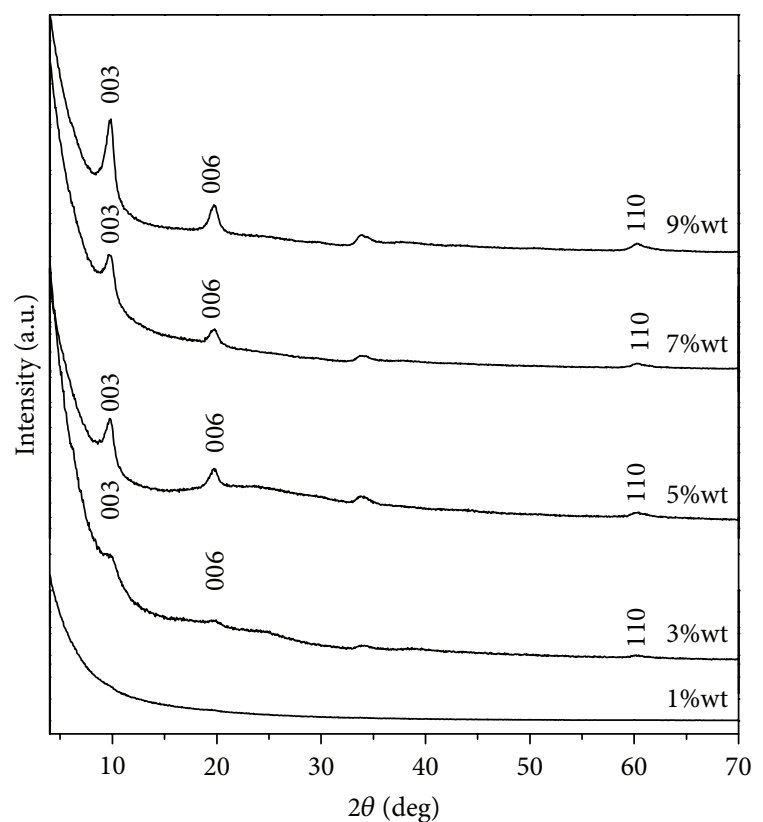

FIGURE 2: XRD patterns of polyvinyl chloride- $\mathrm{Zn} / \mathrm{Al}-\mathrm{NO}_{3}$ at varying concentrations of $\mathrm{LDH}$.

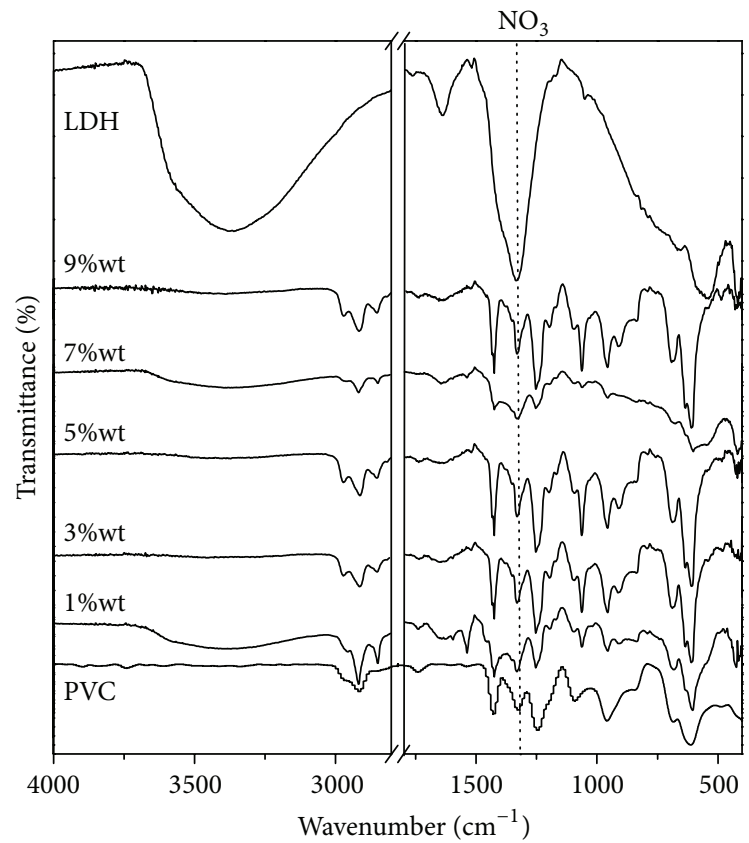

FIGURE 3: FTIR study of polyvinyl chloride- $\mathrm{Zn} / \mathrm{Al}-\mathrm{NO}_{3}$ at varying compositions of LDH.

the diffraction line at half of the maximum intensity in radians (FWHM data converted to radians).

Table 1 and Figure 2 show the XRD patterns for PVC-LDH composites at varying concentrations of LDH.

3.2. Fourier Transform Infrared (FTIR) Spectra Study. Figure 3 shows the FTIR spectrum of the PVC, LDH, and PVC-LDH composite samples. The unexpected broad band
TABLE 1: XRD data of polyvinyl chloride- $\mathrm{Zn} / \mathrm{Al}-\mathrm{NO}_{3}$ composites.

\begin{tabular}{lcc}
\hline Sample & $2 \theta$ & $d$-Spacing \\
\hline $1 \%$ wt & - & - \\
$3 \% \mathrm{wt}$ & 10.01 & 8.83 \\
$5 \% \mathrm{wt}$ & 9.95 & 8.85 \\
$7 \% \mathrm{wt}$ & 9.94 & 8.89 \\
$9 \% \mathrm{wt}$ & 9.94 & 8.89 \\
\hline
\end{tabular}

is attributed to the $\mathrm{O}-\mathrm{H}$ stretching of hydroxyl groups by approximately $3389 \mathrm{~cm}^{-1}$. The nitrate that is intercalated between the interlayers of LDH appeared at $1334 \mathrm{~cm}^{-1}$. The peaks obtained under $800 \mathrm{~cm}^{-1}$ are caused by the metaloxygen vibrations, $\nu(\mathrm{M}-\mathrm{O})$ stretching, and $\nu(\mathrm{M}-\mathrm{O}-\mathrm{H})$ bending [20]. The PVC curve is also shown in Figure 3. Bands in the range of $610-840 \mathrm{~cm}^{-1}$ and $1240-1540 \mathrm{~cm}^{-1}$ are attributed to $\mathrm{C}-\mathrm{Cl}$ stretching and bending of $\mathrm{C}-\mathrm{H}$ bonds, respectively [21]. Another band at $1090 \mathrm{~cm}^{-1}$ is attributed to bending of the $\mathrm{C}-\mathrm{C}$ bond. Figure 3 also shows the FTIR spectrum of the as-synthesised PVC-LDH composites. In general, the spectrums are composed of combined spectral band features of the LDH and PVC. This indicates that PVC coated the surface of the LDH.

3.3. Scanning Electron Microscopy (SEM). Scanning electron microscopy (SEM) images and energy dispersive X-ray spectroscopy (EDX) patterns of the PVC-LDH composites are shown in Figure 4. The SEM images reveal the incorporation of LDH particles in the PVC matrix. Figures 4(a), 4(b), 4(c), 4(d), and 4(e) show PVC as the polymeric matrix with varying concentrations of LDH as the filler at 300x. Figure 4 also shows that there were no aggregates or agglomerates in the composite samples, and the samples were in the shape of a single plate. The elemental analysis of the composites was conducted using the energy dispersive $\mathrm{X}$-ray pattern of the 9\%wt LDH sample (Figure 4(f)). It can be clearly observed that the LDH was not affected by the presence of the PVC components in the composites, where the peaks of different components indicate the presence of filler (LDH) in the PVC matrix.

3.4. Room-Temperature Dielectric Properties. The electromagnetic wave behaviour depends essentially on the dielectric properties (the dielectric constant and the dielectric loss factor). The dielectric constant, $\varepsilon^{\prime}$, is represented by the storage of electromagnetic waves in the material, while the dielectric loss factor, $\varepsilon^{\prime \prime}$, is the dissipation of energy.

Figure 5 shows the variation of the room-temperature dielectric constant and dielectric loss factor of pure LDH in the frequency range of $1 \mathrm{MHz}$ to $1.2 \mathrm{GHz}$. It is clear that the $\mathrm{LDH}$ possesses high dielectric properties, as indicated by the values of the dielectric constant and dielectric loss factor. However, the dielectric constant demonstrated higher values than the dielectric loss factor. The dielectric response of this material structure is believed to be caused by two charge carriers $[6,22]$, the proton and the gallery ions. The proton originates from the polarisation of water clusters in the LDH 


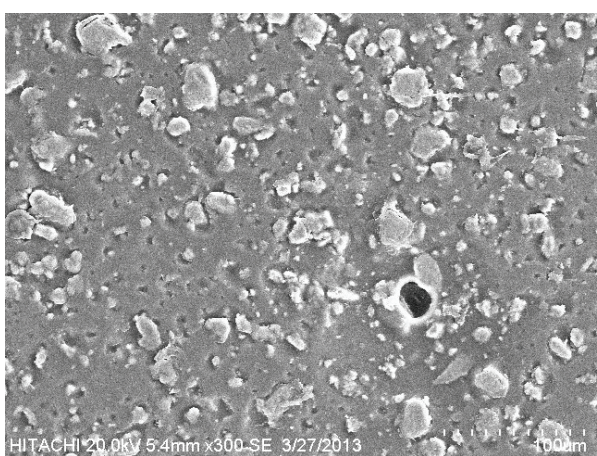

(a)

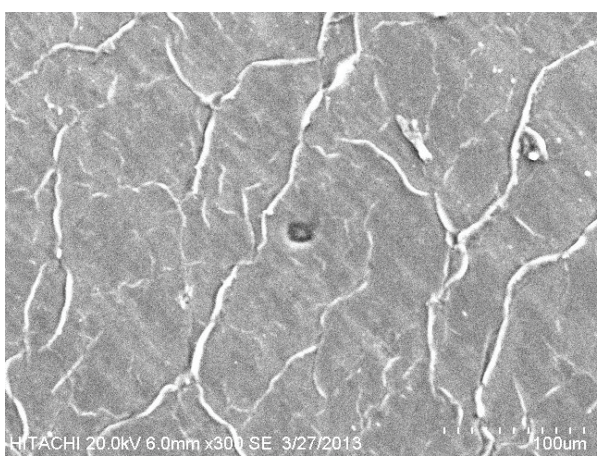

(c)

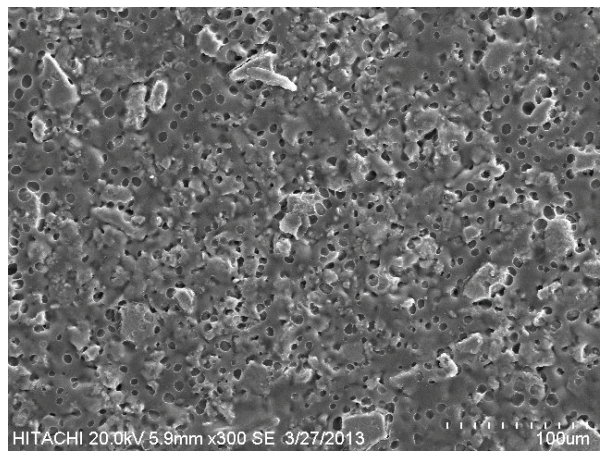

(e)

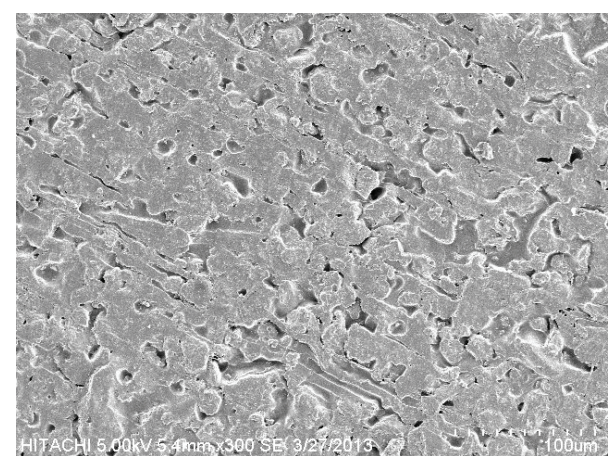

(b)

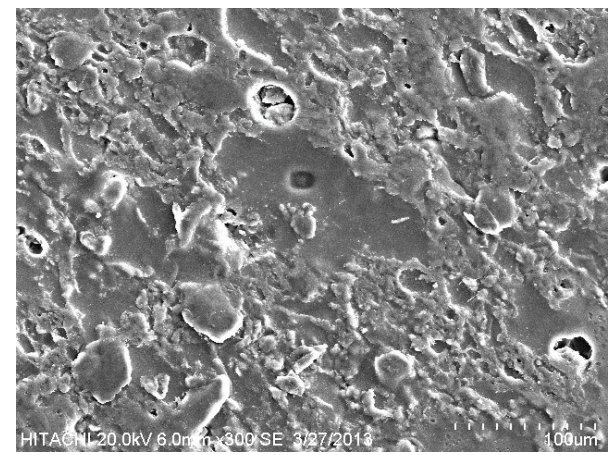

(d)

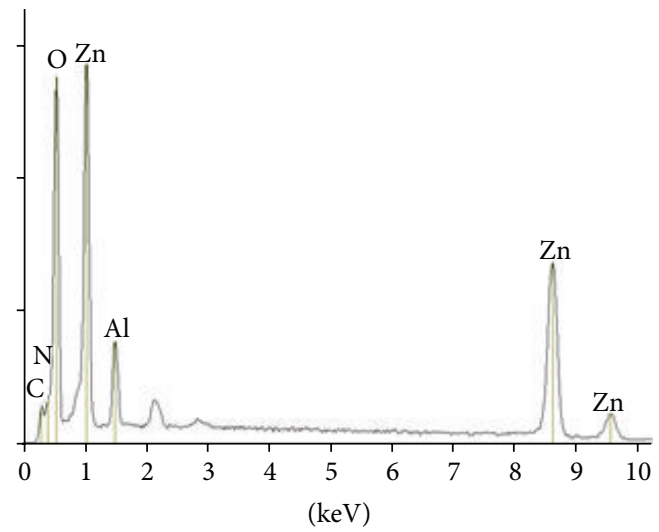

(f)

FIgURE 4: SEM images of (a) 1\%wt, (b) 3\%wt, (c) 5\%wt, (d) 7\%wt, and (e) 9\%wt PVC-LDH, (f) EDX of 9\%wt.

interlayer and the creation of $\mathrm{OH}^{-}$and $\mathrm{OH}_{3}{ }^{+}$at each end of the path along which the proton is transferred. The second carrier is the $\mathrm{NO}_{3}{ }^{-}$, and it serves as a supplemental carrier, moving from its equilibrium position under the influence of the electric field. It should be noted that the dielectric properties of the pure LDH decreased with the frequency increment because of anomalous low frequency dispersion (ALFD), where the current carrier is dominated in the dielectric system [23].

The effect of varying concentrations of $\mathrm{LDH}$ as filler (1\%wt, 3\%wt, 5\%wt, 7\%wt, and $9 \% w t$ ) on both the dielectric constant and the dielectric loss factor of a PVC matrix is shown in Figures 6(a) and 6(b), respectively.

In Figure 6, insignificant changes in the dielectric properties of the pure PVC were observed with good agreement with previous findings [24]. For the PVC-LDH composites, the dielectric properties were enhanced by the varying concentrations of LDH. In the effective medium theory [25], the dielectric properties of polymer-based composites can be increased by the addition of fillers with high dielectric properties. In this study, both a higher dielectric constant and a higher dielectric loss factor were obtained for the composites with higher concentrations of pure LDH. With the addition of only $1 \%$ wt $\mathrm{LDH}$ into the PVC matrix, an increase was observed in both the dielectric constant and the dielectric loss factor. An even higher concentration of LDH resulted in higher dielectric properties. The results suggest that the addition of $\mathrm{LDH}$ to PVC can alter the properties of PVC, transforming it from a nearly stable dielectric material to a dispersive material. Medium-loss materials have 


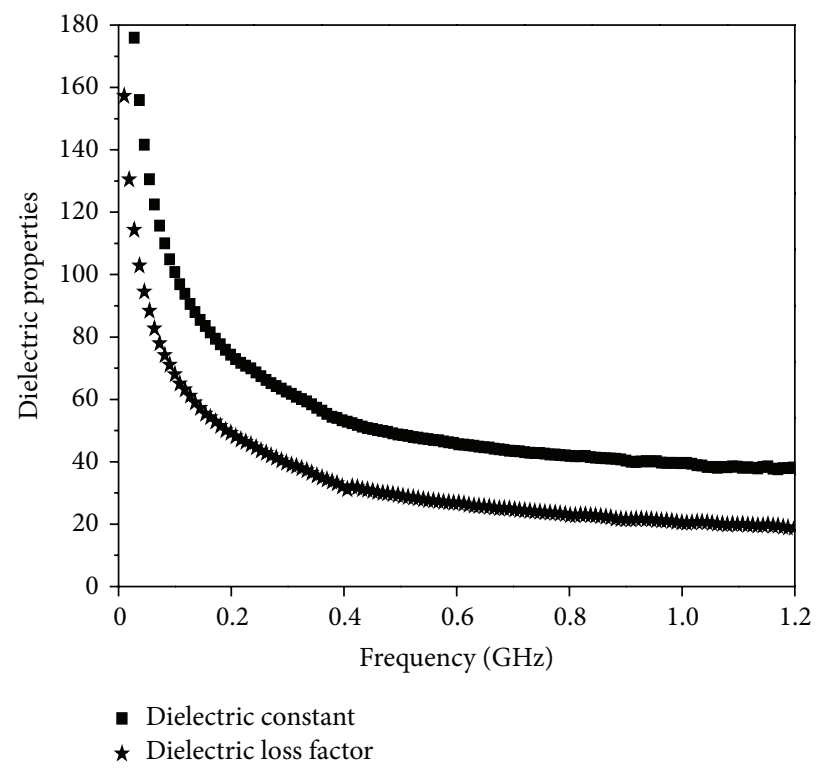

FIGURE 5: Dielectric properties versus frequency of $\mathrm{Zn} / \mathrm{Al}-\mathrm{NO}_{3}$.

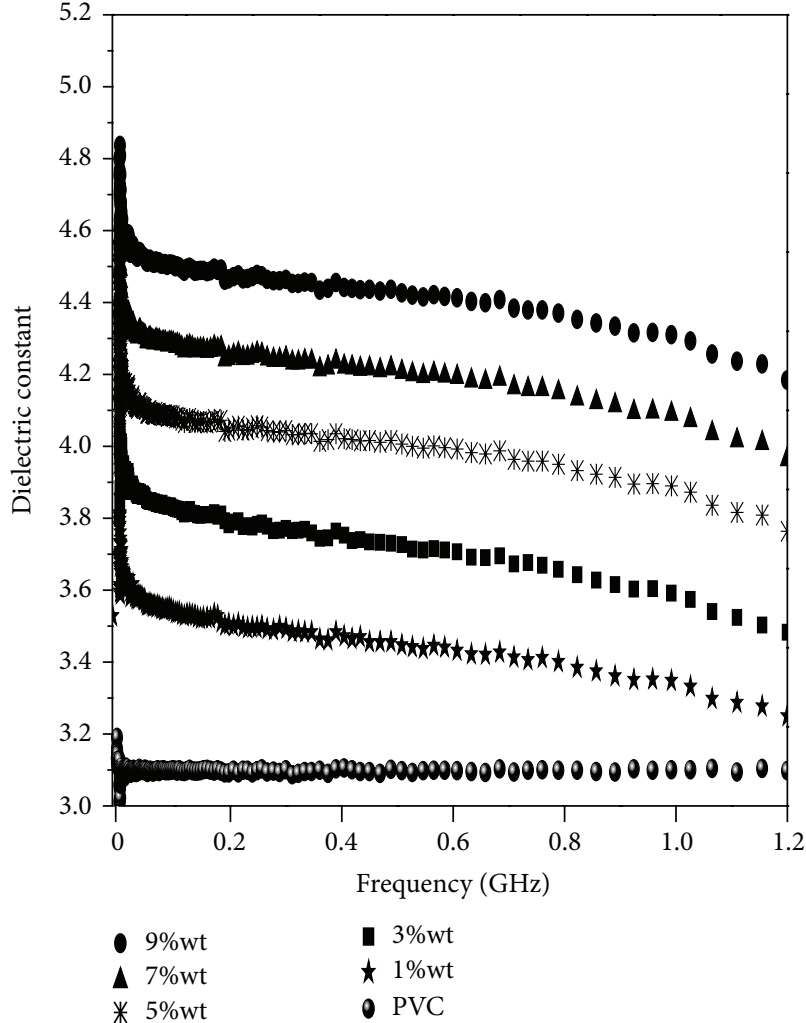

(a)

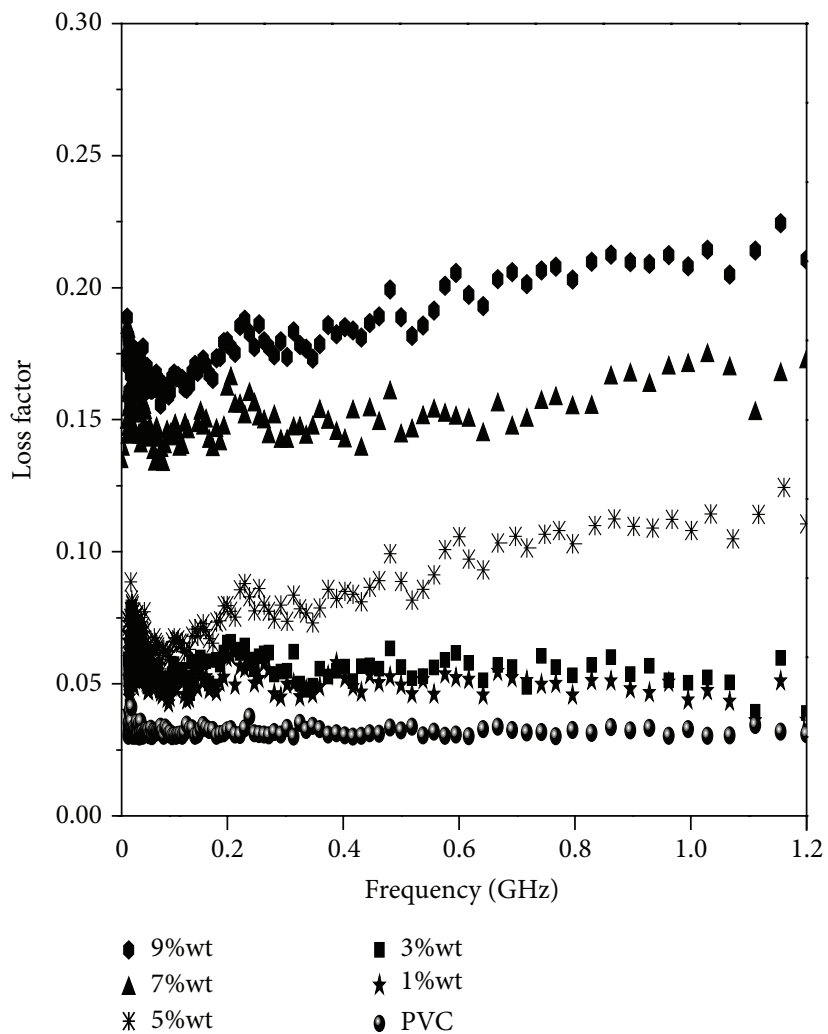

(b)

FIGURE 6: Dielectric properties of polyvinyl chloride- $\mathrm{Zn} / \mathrm{Al}-\mathrm{NO}_{3}$ composites; (a) dielectric constant, (b) dielectric loss factor.

a dielectric loss factor in the range of 0.05 to 0.1 , while highloss materials have a dielectric loss factor above 0.1 [26]. Therefore, by increasing the concentration of pure LDH to $5 \%$ wt or more, the PVC can be easily transformed from a medium-loss to a high-loss material.

\section{Conclusion}

LDH was successfully prepared and different compositions of PVC-LDH composites were obtained using a THF solution. The purity of the prepared materials was investigated using 
XRD and FTIR, while the surface morphology was studied using SEM. The present investigation revealed that the addition of 5\%wt LDH can transform PVC from a medium-loss to a high-loss material. The presence of the LDH filler increases the dielectric loss of these composites, which leads to an increase in the probability that the composites will absorb electromagnetic waves at low microwave frequencies. Hence, these composites are recommended highly for use in electromagnetic interference applications.

\section{Conflict of Interests}

The authors declare that there is no conflict of interests regarding the publication of this paper.

\section{Acknowledgments}

The authors would like to acknowledge the Ministry of Higher Education, Malaysia, for partial support of the current study. The authors would also like to acknowledge the Institute of Advanced Technology, Universiti Putra Malaysia, for the use of laboratory facilities.

\section{References}

[1] A. William Coaker, "Fire and flame retardants for PVC," Journal of Vinyl and Additive Technology, vol. 9, no. 3, pp. 108-115, 2003.

[2] A. J. Bur, "Dielectric properties of polymers at microwave frequencies: a review," Polymer, vol. 26, no. 7, pp. 963-977, 1985.

[3] B. L. Funt, "Dielectric dispersion in solid polyvinyl butyral," Canadian Journal of Chemistry, vol. 30, no. 2, pp. 84-91, 1952.

[4] E. M. Amrhein and F. H. Mueller, "Background loss of amorphous dielectrics in the high frequency and microwave region," Transactions of the Faraday Society, vol. 64, pp. 666-676, 1968.

[5] Y. Ishida, "A note on the mechanism of the dielectric absorption of polyvinyl chloride," Colloid \& Polymer Science, vol. 171, no. 1, pp. 71-72, 1960.

[6] A. A. A. Ahmed, Z. A. Talib, and M. Z. B. Hussein, "Thermal, optical and dielectric properties of $\mathrm{Zn}$-Al layered double hydroxide," Applied Clay Science, vol. 56, pp. 68-76, 2012.

[7] S. Y. Ryu, M. J. Yoon, J. H. Choy et al., "Optical properties of oxotitanium (IV) meso-tetrakis (4-sulfonatophenyl) porphyrin intercalated into the layered double hydroxides (LDH) studied by laser spectroscopy," Bulletin of the Korean Chemical Society, vol. 24, no. 4, pp. 446-452, 2003.

[8] C. Li, L. Wang, D. G. Evans, and X. Duan, "Thermal evolution and luminescence properties of $\mathrm{Zn}$-Al-layered double hydroxides containing europium(III) complexes of ethylenediaminetetraacetate and nitrilotriacetate," Industrial and Engineering Chemistry Research, vol. 48, no. 4, pp. 2162-2171, 2009.

[9] F. Lv, Y. Wu, Y. Zhang, J. Shang, and P. K. Chu, "Structure and magnetic properties of soft organic $\mathrm{ZnAl}-\mathrm{LDH} /$ polyimide electromagnetic shielding composites," Journal of Materials Science, vol. 47, no. 4, pp. 2033-2039, 2012.

[10] S. V. Levchik and E. D. Weil, "Overview of the recent literature on flame retardancy and smoke suppression in PVC," Polymers for Advanced Technologies, vol. 16, no. 10, pp. 707-716, 2005.

[11] G. Montaudo and C. Puglisi, "Evolution of aromatics in the thermal degradation of poly(vinyl chloride): a mechanistic study," Polymer Degradation and Stability, vol. 33, no. 2, pp. 229262, 1991.
[12] B. Li, "Influence of polymer additives on thermal decomposition and smoke emission of poly(vinyl chloride)," Polymer Degradation and Stability, vol. 82, no. 3, pp. 467-476, 2003.

[13] J. W. Burley and P. D. Clifford, "Extending the use of zinccontaining biocides in PVC," Journal of Vinyl and Additive Technology, vol. 10, no. 2, pp. 95-98, 2004.

[14] W. H. Cheng and Y. C. Liang, "Catalytic pyrolysis of polyvinylchloride in the presence of metal chloride," Journal of Applied Polymer Science, vol. 77, no. 11, pp. 2464-2471, 2000.

[15] R. F. Grossman, "Acid absorbers as PVC costabilizers," Journal of Vinyl and Additive Technology, vol. 6, no. 1, pp. 4-6, 2000.

[16] E. Santamaria, M. Edge, N. S. Allen, H. B. Harvey, M. Mellor, and J. Orchison, "New insights into the degradation mechanism of poly (vinyl chloride), based on the action of novel costabilizers. I," Journal of Applied Polymer Science, vol. 93, no. 6, pp. 2731-2743, 2004.

[17] L. Van Der Ven, M. L. M. Van Gemert, L. F. Batenburg et al., "On the action of hydrotalcite-like clay materials as stabilizers in polyvinylchloride," Applied Clay Science, vol. 17, no. 1-2, pp. 25$34,2000$.

[18] X. Wang and Q. Zhang, "Effect of hydrotalcite on the thermal stability, mechanical properties, rheology and flame retardance of poly(vinyl chloride)," Polymer International, vol. 53, no. 6, pp. 698-707, 2004.

[19] S. H. H. Al Ali, M. Al-Qubaisi, M. Z. Hussein, Z. Zainal, and M. N. Hakim, "Preparation of hippurate-zinc layered hydroxide nanohybrid and its synergistic effect with tamoxifen on HepG2 cell lines," International Journal of Nanomedicine, vol. 6, no. 1, pp. 3099-3111, 2011.

[20] H. Chai, X. Xu, Y. Lin, D. G. Evans, and D. Li, "Synthesis and UV absorption properties of 2,3-dihydroxynaphthalene-6sulfonate anion-intercalated $\mathrm{Zn}$-Al layered double hydroxides," Polymer Degradation and Stability, vol. 94, no. 4, pp. 744-749, 2009.

[21] S. Ramesh, K. H. Leen, K. Kumutha, and A. K. Arof, "FTIR studies of PVC/PMMA blend based polymer electrolytes," Spectrochimica Acta Part A: Molecular and Biomolecular Spectroscopy, vol. 66, no. 4-5, pp. 1237-1242, 2007.

[22] V. Mehrotra, Intercalation of layered silicates, layered double hydroxides, and lead iodide: synthesis, characterization and properties [Ph.D. thesis], Cornell University, 1992.

[23] A. K. Jonscher, "Dielectric relaxation in solids," Journal of Physics D: Applied Physics, vol. 32, no. 14, pp. R57-R70, 1999.

[24] Y. Ishida, M. Matsuo, and K. Yamafuji, "Dielectric behaviors of some polyvinyl esters," Kolloid-Zeitschrift \& Zeitschrift für Polymere, vol. 180, no. 2, pp. 108-114, 1962.

[25] T. C. Choy, Effective Medium Theory: Principles and Applications, vol. 102, Oxford University Press, Oxford, UK, 1999.

[26] D. Jablonski, "Attenuation characteristics of circular dielectric waveguide at $\mathrm{m}$ illimeter wavelengths," IEEE Transactions on Microwave Theory and Techniques, vol. 26, no. 9, pp. 667-671, 1978. 

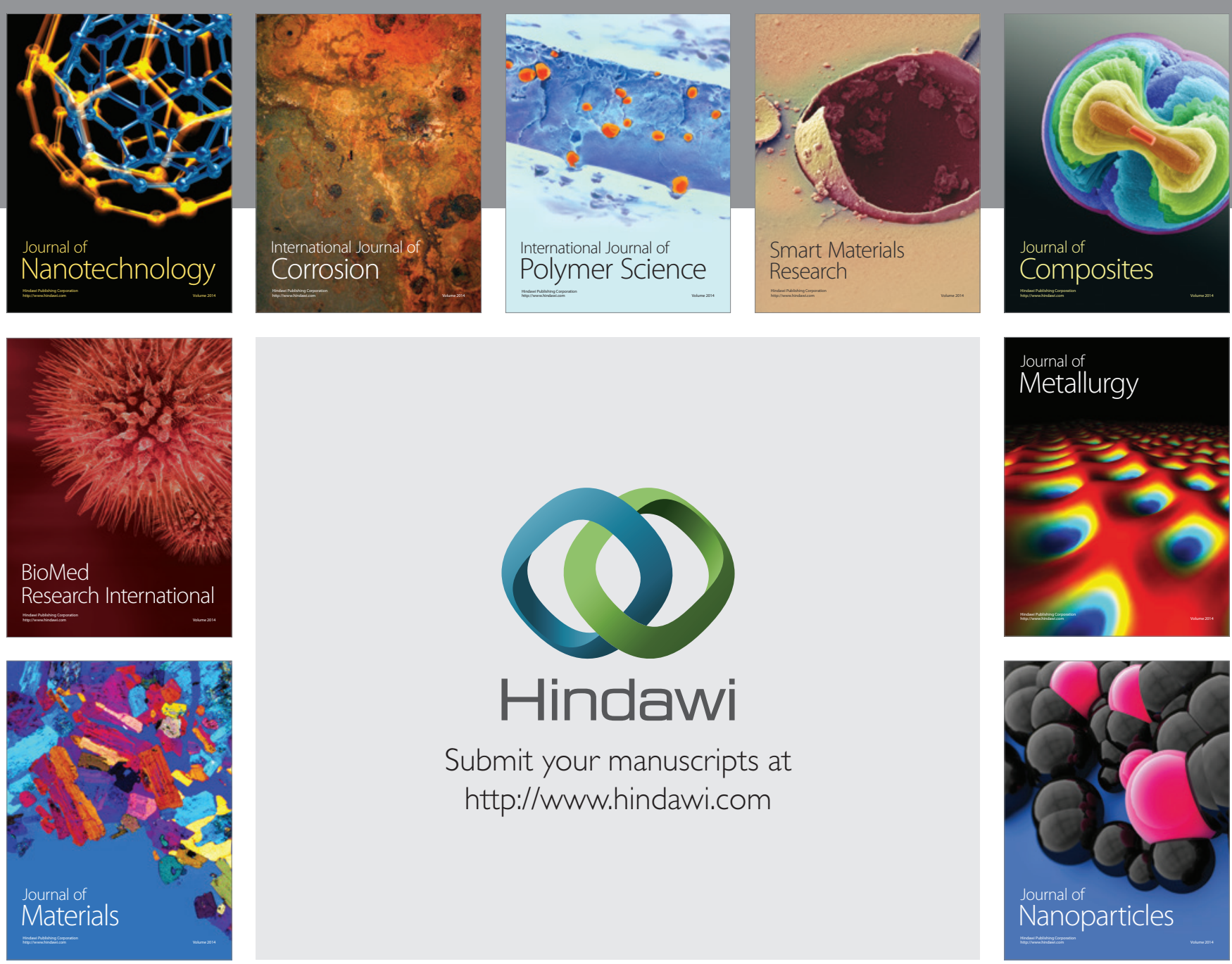

Submit your manuscripts at http://www.hindawi.com
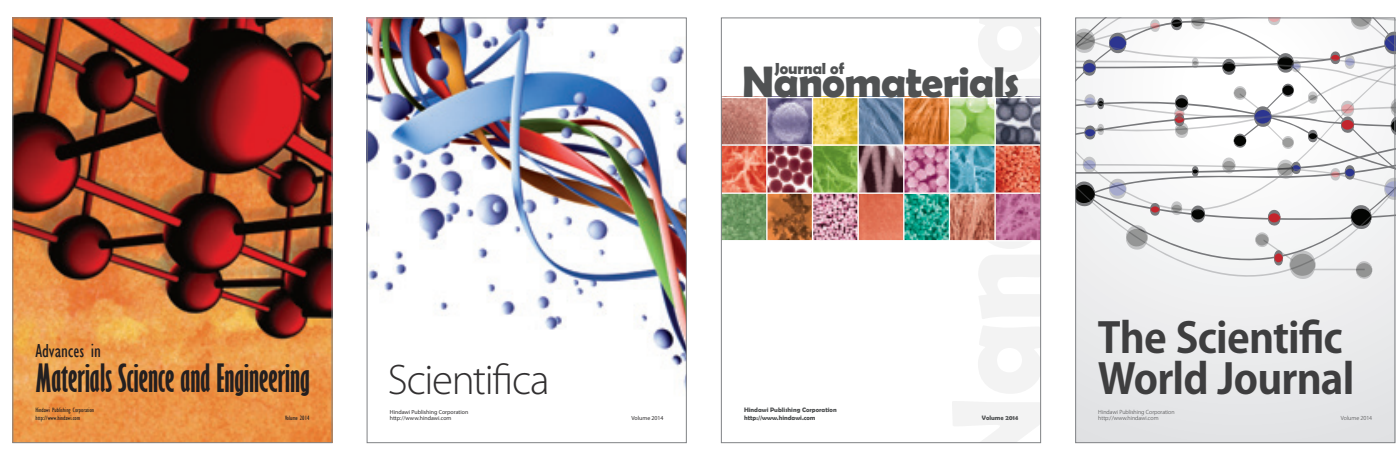

\section{The Scientific World Journal}
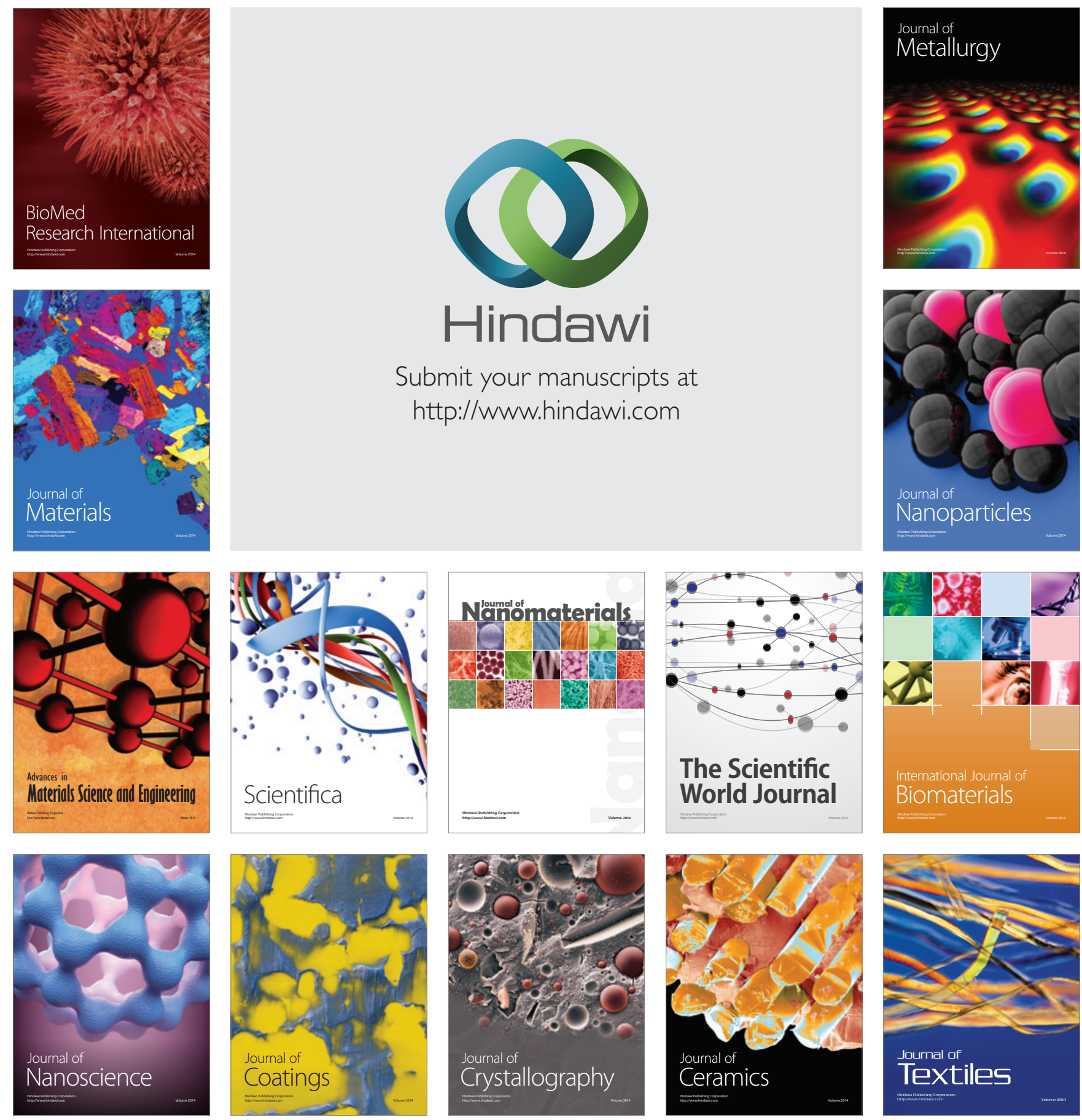